\section{Postbloom Thinning Response of 'Bartlett' Pears to Abscisic Acid}

Matthew Arrington

Department of Horticulture, Oregon State University, Mid-Columbia Agricultural Research and Extension Center, 3005 Experiment Station Drive, Hood River, OR 97031

\section{Mateus S. Pasa}

Department of Horticulture, Santa Catarina Agricultural Research and Extension Agency, Experimental Station of São Joaquim, 102 João Araújo Lima Street, São Joaquim 88600000, Brazil

Todd C. Einhorn ${ }^{1,2}$

Department of Horticulture, Oregon State University, Mid-Columbia Agricultural Research and Extension Center, 3005 Experiment Station Drive, Hood River, OR 97031

Additional index words. European pear, Pyrus communis, crop load management, fruit set, photosynthesis

\begin{abstract}
Postbloom thinning of 'Bartlett' pears (Pyrus communis L.) is required to produce fruit of commercially acceptable size. In the Pacific Northwestern United States, low temperatures during early stages of pear fruitlet development often limit the efficacy of commercial thinning compounds. Hand thinning, therefore, remains the standard crop load management practice. Chemical thinning protocols are necessary to reduce the cost and dependence on hand labor. The plant hormone abscisic acid (ABA) was evaluated over multiple years in several 'Bartlett' pear orchards. ABA was applied to whole canopies at variable rates $(50-500 \mathbf{~ p p m})$ when fruit diameter was generally between 10 and $12 \mathrm{~mm}$. In three of four trials, ABA thinned in a dose-dependent manner. The relative degree of thinning for a given dose, however, was inconsistent among trials. Trees treated with ABA had a higher proportion of blank and single-fruited spurs than the control. Net photosynthesis $\left(P_{n}\right)$ of single leaves was reduced $75 \%$ to $90 \%$ within one day of $\mathrm{ABA}$ application but gradually returned to $\approx 80 \%$ of control levels within 7 days and fully recovered by $\approx 14$ days. Slightly greater and longer lasting $P_{n}$ inhibition occurred with increasing ABA dose. Fruit weight and return bloom generally increased with increasing ABA rate. Fruit quality, when measured, was unaffected by ABA treatments. Inconsistent thinning response with $\mathrm{ABA}$ may be attributed to environmental factors, biological factors, or both.
\end{abstract}

The west coast states CA, OR, and WA account for $\approx 97 \%$ of the U.S. fresh market 'Bartlett' pear crop (U.S. Department of Agriculture National Agricultural Statistics Service, 2016). About half of those pears are produced in the Pacific Northwest (PNW) where the cultural practice of hand thinning is

Received for publication 22 Aug. 2017. Accepted for publication 6 Nov. 2017.

We thank Gorham Blaine for providing commercial orchard sites to accommodate research trials. We thank the NW Pear Bureau and the Washington Tree Fruit Research Commission for project funding.

Mention of a trademark, proprietary product, or vendor does not constitute a guarantee or warranty of the product by Oregon State University and does not imply its approval to the exclusion of other products or vendors that also may be suitable.

${ }^{1}$ Current address: Department of Horticulture, Michigan State University, 1066 Bogue Street, East Lansing, MI 48824.

${ }^{2}$ Corresponding author. E-mail: einhornt@msu. edu.

HortScience Vol. 52(12) December 2017 pear trees to increased risk of fire bligh (Erwinia amylovora) infection, although this effect was not reported by Seehuber et al. (2015). Irrespective, chemical thinning approaches have been far more common for pear (Wertheim, 2000).

Thinning compounds differ with respect to their mode of action. Some chemicals applied around flowering [i.e., fish oil and lime sulfur (Yoder et al., 2009); ammonium thiosulfate (ATS) (Wertheim, 2000)] are caustic and primarily serve to damage tissues of reproductive organs. Bound and Mitchell (2002) reported significantly reduced fruit set of 'Packham's Triumph' pear when ATS was applied at low concentrations $(0.5 \%$ to $1.5 \%)$ at $20 \%$ and $50 \%$ of full bloom, with two applications improving the response. ATS concentrations of $3 \%$ were phytotoxic to other pear cultivars (Wertheim, 2000). Pears are generally thinned during postbloom developmental stages using chemicals that alter the source-to-sink ratio (Lakso et al., 2006) or hormonal balance (Bangerth, 2000). With the exception of ethephon, which is seldom used to thin pears, most of the hormone-like thinners are applied when fruit diameter is 10-12 mm. The cytokinin 6-benzyladenine (BA) is the most extensively used pear thinner throughout the world (Asín et al., 2009; Curetti et al., 2010; Dussi, 2011; Gimenez et al., 2009; Greene, 2012; Maas and van der Steeg, 2011; Theron et al., 2011; Wertheim, 2000). The auxin naphthaleneacetic acid (NAA) and its amide (NAD) also thin pears although results have been variable (Asín et al., 2009; Theron et al., 2011; Wertheim, 2000) and adverse effects such as induced premature ripening and reduced storage life of 'Bartlett' have been observed (Lombard and Grim, 1966). A critical drawback of BA and NAA/NAD is the relatively high temperature requirement for effective foliar penetration, uptake, and activity (Black et al., 1995; Edgerton and Haeseler, 1959; Luckwill and Lloyd-Jones, 1962; Wertheim, 2000). Thinning activity of BA was associated with temperatures $>18{ }^{\circ} \mathrm{C}$ (Bubán, 2000). Foliar penetration of NAA was determined to increase 3 -fold between $25{ }^{\circ} \mathrm{C}$ and $35{ }^{\circ} \mathrm{C}$ (Greene and Bukovac, 1971). Thus, predictable thinning outcomes can be difficult to achieve in cooler climates. Alternative thinning chemistries are needed.

Abscisic acid is a plant hormone associated with abscission and plant dormancy (Taiz and Zeiger, 2010). ABA also regulates stomatal aperture during periods of drought to prevent plant desiccation (Davies and Zhang, 1989). Exogenously applied ABA can mimic drought stress when soil moisture is nonlimiting (Correia et al., 1999). An obvious consequence of stomatal closure is reduced carbon fixation, which has been associated with improved thinner efficacy (Lakso, 2011; Lakso et al., 2006; Untiedt and Blanke, 2001). Thus, ABA may enhance fruit abscission by inducing a carbohydrate (CHO) deficit. ABA has also been associated with increased ethylene production and abscission of peach when treated at pit hardening (Giovanaz et al., 2015) and mature apples (Edgerton, 1971) but did not appear to 
explain ABA-induced pear fruitlet abscission when trees were treated $10 \mathrm{~d}$ after full bloom (dafb) (Einhorn and Arrington, 2017). Several researchers have sought to exploit these mechanisms to thin apple (Greene et al., 2011; McArtney et al., 2014) and pear (Greene, 2012). McArtney et al. (2014) reported reduced stomatal conductance $\left(g_{\mathrm{s}}\right)$, and by extension, $P_{\mathrm{n}}$ (Lakso, 1994), of apple leaves treated with ABA, although this was not always associated with thinning. Greene (2012) observed consistent thinning when ABA was applied to 'Bartlett' pear, both alone and in combination with BA. ABA $(500 \mathrm{ppm})$ reduced control fruit set by $37 \%$, $77 \%$, and $99 \%$ when applied at full bloom, petal fall, and $10 \mathrm{~mm}$ diameter phenology stages, respectively (Greene, 2012). Because these experiments were all conducted in the Eastern United States, and may not apply to the PNW, our primary objective was to evaluate $\mathrm{ABA}$ performance as a postbloom thinner in a major pear-producing region of the PNW.

\section{Materials and Methods}

Planting material, treatments, and experimental design. Four experiments were carried out in three 'Bartlett' pear orchards in Hood River and Parkdale, OR, between 2012 and 2014. In all trials, concentrations of ABA (ProTone; Valent BioSciences, Walnut Creek, CA) were combined with a surfactant (Sil 100; Clariant Corp., Mount Holly, NC) at $0.1 \%$ (v:v) and applied to drip between $\approx 0600$ and $1000 \mathrm{HR}$ using a hydraulic, pressurized spray gun. Dilute handgun applications generally require greater spray volume per tree than would be applied in a commercial application and may limit direct extrapolation of these results to commercial practices. Depending on the trial, ABA was applied between petal fall and $10-12 \mathrm{~mm}$ fruit diameter; actual dates varied according to forecasted precipitation and wind conditions. In each experiment, trees were preselected for uniformity of bloom and canopy size and then randomly assigned treatments. For all experiments, applications were made under calm conditions (i.e., wind speeds of $\left.<5 \mathrm{~km} \cdot \mathrm{h}^{-1}\right)$. All other production practices were performed according to industry standards.

Expt. 1. In 2012, an eighth-leaf 'Bartlett'/ ' $\mathrm{OH} \times \mathrm{F} \mathrm{87}$ ' orchard $(3 \times 5 \mathrm{~m}$; 666 trees/ha) was selected in Hood River, OR, at the Oregon State University Mid-Columbia Agricultural Research and Extension Center (MCAREC) (long. 45.68, lat. 121.51). Soil is a Van Horn fine sandy loam. Treatments were arranged in a randomized complete block design (RCBD) with four single-tree replications. Blocks comprised single rows and were separated by three guard rows. Within blocks (i.e., rows), treatment trees were separated by a minimum of one guard tree to reduce the risk of spray contamination. The following treatments were applied: 1) control, 2) deionized (DI) water $+0.1 \%$ (v:v) surfactant, 3) 125 ppm ABA, 4) 250 ppm ABA, and 5) 500 ppm ABA. Treatments were applied $21 \mathrm{dafb}$. No significant differences were observed between the control and control + surfactant for any of the measured parameters. Results, therefore, are only provided for the control. In all ensuing experiments, the water + surfactant treatment was omitted from the treatment design. All ABA concentrations continued to be combined with $0.1 \%$ (v:v) surfactant.

Expt. 2. In 2013, an 18-year-old 'Bartlett'/ ' $\mathrm{OH} \times \mathrm{F} 97$ ' pear orchard $(2.5 \times 5.5 \mathrm{~m} ; 727$ trees/ha) was selected in Hood River, OR, at the MCAREC. Soil is a Van Horn fine sandy loam. Treatments were arranged in an RCBD with four single-tree replications. Blocks comprised single rows and were separated by five guard rows. Within blocks (i.e., rows), treatment trees were separated by a minimum of one guard tree to reduce the risk of spray contamination. Treatments consisted of a control, 50, 100, 150, and 200 ppm ABA. Applications were made 22 dafb.

Expt. 3. In 2013, a 10th-leaf commercial 'Bartlett'/' $\mathrm{OH} \times \mathrm{F} 97$ ' pear orchard $(3 \times 6 \mathrm{~m}$; 556 trees/ha) was selected in Parkdale, OR (long. 45.29, lat. 121.34). Soil is a Hutson fine sandy loam. Treatment trees were confined to three rows and were arranged in a complete randomized design (CRD) with four replications, each comprising two trees. A minimum of one guard tree was maintained in all directions. The following treatments were applied: 1) control, 2) 50 ppm ABA, 3) 100 ppm ABA, 4) 200 ppm ABA, and 5) 400 ppm ABA. Applications were made $20 \mathrm{dafb}$.

Expt. 4. In 2014, a trial was established in the orchard described in Expt. 2 using trees not previously treated with thinning compounds. Treatments were arranged in an RCBD with four replications each comprising two trees. Blocks comprised single rows and were separated by five guard rows. Within blocks (i.e., rows), treatment trees were separated by a minimum of one guard tree to reduce the risk of spray contamination. The following treatments were applied: 1)

Table 1. Expt. 1. Effect of 2012 abscisic acid (ABA) applications ( $21 \mathrm{~d}$ after full bloom) on fruit set, number of fruit hand thinned, number of fruit harvested, yield, average fruit weight, and return bloom of eighth-leaf 'Bartlett'/' $\mathrm{OH} \times \mathrm{F} 97$ ' pear trees $(3 \times 5 \mathrm{~m} ; 666$ trees/ha) at the Oregon State University Mid-Columbia Agricultural Research and Extension Center in Hood River, OR. Data are means of four single-tree replications.

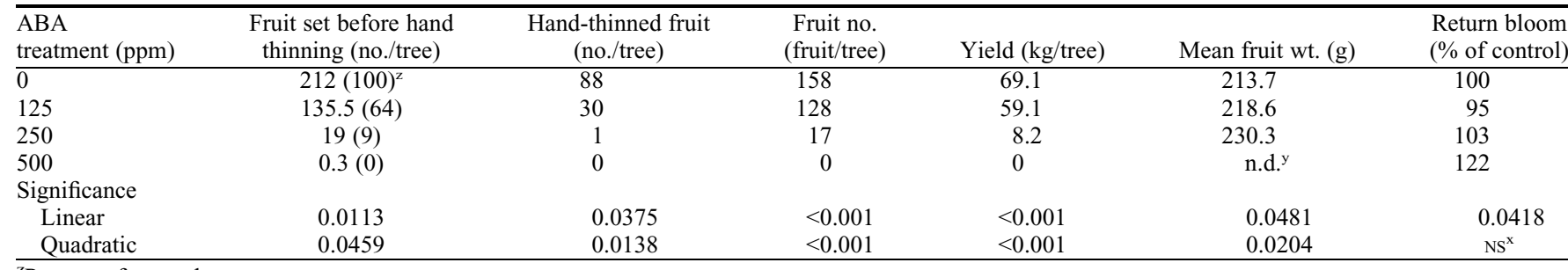

${ }^{\mathrm{z}}$ Percent of control.

${ }^{\mathrm{y}}$ n.d. $=$ no data because of no fruit at harvest.

$\mathrm{x}_{\mathrm{NS}}=$ nonsignificant.

Table 2. Expt. 2. Effect of 2013 abscisic acid (ABA) applications ( $22 \mathrm{~d}$ after full bloom) on fruit set, number of fruit hand thinned, number of fruit harvested, yield, average fruit weight, and return bloom of 18-year-old 'Bartlett'/' $\mathrm{OH} \times \mathrm{F}$ 97' pear trees $(2.5 \times 5.5 \mathrm{~m} ; 727$ trees/ha) at the Oregon State University MidColumbia Agricultural Research and Extension Center in Hood River, OR. Data are means of four two-tree replications.

\begin{tabular}{|c|c|c|c|c|c|c|}
\hline $\begin{array}{l}\mathrm{ABA} \\
\text { treatment }(\mathrm{ppm})\end{array}$ & $\begin{array}{c}\text { Fruit set } \\
\text { (no. fruit/cluster) }\end{array}$ & $\begin{array}{l}\text { Hand-thinned fruit } \\
\text { (no./tree) }\end{array}$ & $\begin{array}{c}\text { Fruit no. } \\
\text { (fruit/tree) }\end{array}$ & $\begin{array}{c}\text { Yield } \\
(\mathrm{kg} / \text { tree })\end{array}$ & Mean fruit wt $(\mathrm{g})$ & $\begin{array}{l}\text { Return bloom } \\
(\% \text { of control) }\end{array}$ \\
\hline$\overline{0}$ & 0.56 & 32 & 254 & 54.1 & 212.5 & 100 \\
\hline 50 & 0.74 & 72 & 277 & 64.3 & 231 & 81 \\
\hline 100 & 0.61 & 51 & 227 & 50.2 & 220.2 & 102 \\
\hline 150 & 0.55 & 30 & 240 & 58.1 & 241.6 & 87 \\
\hline 200 & 0.72 & 69 & 257 & 59.5 & 229.5 & 97 \\
\hline \multicolumn{7}{|l|}{ Significance } \\
\hline Linear & $\mathrm{NS}^{\mathrm{z}}$ & NS & NS & NS & 0.0206 & NS \\
\hline Quadratic & NS & NS & NS & NS & NS & NS \\
\hline
\end{tabular}

${ }_{\mathrm{NS}}=$ nonsignificant. 
Table 3. Expt. 3. Effect of 2013 abscisic acid (ABA) applications ( $20 \mathrm{~d}$ after full bloom) on fruit set, number of fruit hand thinned, number of fruit harvested, yield, fruit weight, and return bloom of 10th leaf 'Bartlett'/' $\mathrm{OH} \times \mathrm{F} 97$ ' pear trees $(3 \times 6 \mathrm{~m} ; 556$ trees/ha) at a commercial orchard in Parkdale, OR. Data are means of four two-tree replications.

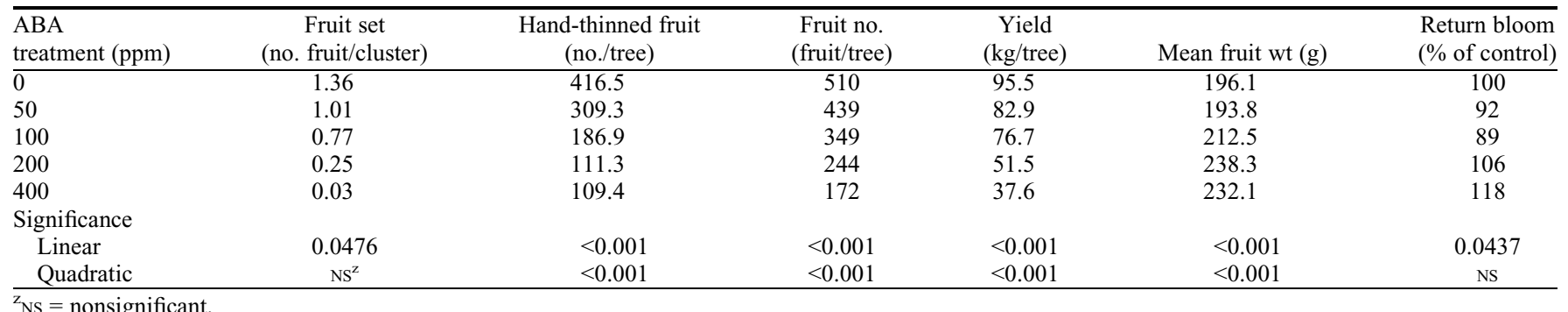

Table 4. Expt. 4. Effect of 2014 abscisic acid (ABA) applications ( $8 \mathrm{~d}$ after full bloom) on fruit set, number of fruit at harvest, yield, average fruit weight, and return bloom of 19-year-old 'Bartlett'/' $\mathrm{OH} \times \mathrm{F}$ 97' pear trees $(2.5 \times 5.5 \mathrm{~m} ; 727$ trees/ha $)$ at the Oregon State University Mid-Columbia Agricultural Research and Extension Center in Hood River, OR. Data are means of four two-tree replications.

\begin{tabular}{|c|c|c|c|c|c|}
\hline ABA treatment (ppm) & Fruit set (no. fruit/cluster) & Fruit no. (fruit/tree) & Yield (kg/tree) & Mean fruit wt $(\mathrm{g})$ & Return bloom (\% of control) \\
\hline 50 & 0.7 & 458 & 91 & 198.5 & 144 \\
\hline 100 & 0.64 & 450 & 85 & 188.6 & 136 \\
\hline 200 & 0.59 & 480 & 92.5 & 192.4 & 181 \\
\hline \multicolumn{6}{|l|}{ Significance } \\
\hline Linear & $<0.001$ & 0.0308 & 0.0342 & $\mathrm{NS}^{\mathrm{z}}$ & 0.0468 \\
\hline Quadratic & $<0.001$ & NS & NS & NS & NS \\
\hline
\end{tabular}

$\overline{\mathrm{z}} \mathrm{Q}=$ nonsignificant.

Table 5. The effect of 2014 abscisic acid applications on harvest and postharvest 'Bartlett' pear fruit quality. Postharvest analyses were performed after $60 \mathrm{~d}$ of regular air (RA) cold storage at $-1{ }^{\circ} \mathrm{C},>95 \%$ relative humidity and after a ripening period of $5 \mathrm{~d}$ at $20^{\circ} \mathrm{C}$. Data are means of four replications.

\begin{tabular}{|c|c|c|c|c|c|c|c|c|c|}
\hline \multirow[b]{2}{*}{$\mathrm{ABA}$ treatment $(\mathrm{ppm})$} & \multicolumn{3}{|c|}{ Harvest } & \multicolumn{3}{|c|}{$60 \mathrm{~d}$ RA storage } & \multicolumn{3}{|c|}{$60 \mathrm{~d}$ RA storage plus $5 \mathrm{~d}$ ripening } \\
\hline & $\overline{\mathrm{FF}(\mathrm{kg})}$ & SSC (\%) & TA (\%) & $\overline{\mathrm{FF}(\mathrm{kg})}$ & SSC (\%) & TA (\%) & $\mathrm{FF}(\mathrm{kg})$ & SSC (\%) & TA (\%) \\
\hline 50 & 8.1 & 12.5 & 0.33 & 7.7 & 13.4 & 0.3 & 1.6 & 13.8 & 0.24 \\
\hline 400 & 8.3 & 13.9 & 0.28 & 7.9 & 14.1 & 0.28 & 1.5 & 13.5 & 0.26 \\
\hline \multicolumn{10}{|l|}{ Significance } \\
\hline Linear & $\mathrm{NS}^{\mathrm{z}}$ & NS & NS & NS & NS & NS & NS & NS & NS \\
\hline
\end{tabular}

$\mathrm{FF}=$ fruit firmness; $\mathrm{SSC}=$ soluble solids concentration; TA $=$ titratable acidity.

$\mathrm{z}_{\mathrm{NS}}=$ nonsignificant.

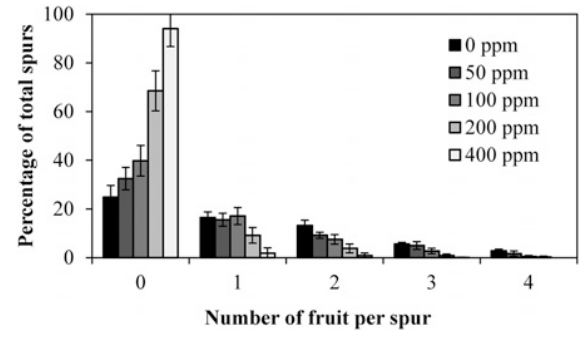

Fig. 1. The effect of abscisic acid rate $(0,50,100$, 200 , and $400 \mathrm{ppm}$ ) on the number of fruit retained per spur on 'Bartlett' pear limbs in Expt. 3. Measurements were taken $40 \mathrm{~d}$ after full bloom following natural fruit drop but before hand thinning. Data are means of four replications ( $n=4$ limbs, each with $\approx 40$ spurs). Vertical bars are \pm 1 SE.

control, 2) $50 \mathrm{ppm} \mathrm{ABA,} \mathrm{3)} 100 \mathrm{ppm} \mathrm{ABA,} \mathrm{4)}$ 200 ppm ABA, and 5) 400 ppm ABA. Applications were made $8 \mathrm{dafb}$.

Flowering and fruiting. For Expts. 2-4, four scaffold limbs per replication were selected at bloom. Scaffolds possessed a minimum of
40 clusters and provided $\approx 200$ flower clusters for fruit set estimates per replication. After June drop ( $\approx 40 \mathrm{dafb})$, the number of fruit on each scaffold limb was counted and fruit set was expressed as the number of fruit per flower cluster. For Expt. 3, all spurs on selected scaffolds were further classified based on the number of fruit remaining at 40 dafb. In Expt. 1, flower clusters were not counted at bloom and fruit set was expressed as the number of total fruit per tree after June drop, but before hand thinning, relative to the control fruit set. For all experiments, trees were hand thinned, if necessary, between 40 and $50 \mathrm{dafb}$ according to industry standards by reducing the number of fruit per flower cluster to one or two. In cases where thinning was excessive, hand thinning was still performed if greater than two fruit per cluster remained after June drop. The number of fruit removed by hand was recorded. Trees in Expt. 4 were not hand thinned. Tree yield was determined by weighing the total number of fruit harvested per tree in a single harvest when fruit reached commercial maturity [i.e., fruit firmness (FF) between 8.6 and $7.6 \mathrm{~kg}$ ].
Average fruit weight was determined by weighing individual fruit from a random 50fruit sample per replication. Return bloom was determined the year after treatment applications from the same limbs used to estimate fruit set by dividing the number of flower clusters counted per limb by the total number of spurs present on each limb. Because 'Bartlett' also fruits on terminal positions of 1-year shoots, the number of clusters per 1-year-old shoot was also determined, but these data were not included in the analysis because a limited number of shoots were observed per scaffold and their presence was inconsistent from limb to limb. Fruit set data were expressed as a percentage of control return bloom.

Fruit quality. Fruit quality attributes were measured in Expt. 4 only. Twenty fruit per replication were sampled at harvest and 30 fruit per replication were stored in regular air (RA) $\left[-1{ }^{\circ} \mathrm{C}\left( \pm 0.5{ }^{\circ} \mathrm{C}\right),>95 \%\right.$ relative humidity $(\mathrm{RH})]$ for $60 \mathrm{~d}$ before postharvest evaluations. At all sample dates, FF was measured on two sites per fruit (opposite one another) using an automated penetrometer 
(Fruit Texture Analyzer; Güss Manufacturing, Strand, South Africa) after removing $\mathrm{a} \approx 5 \mathrm{~cm}^{2}$ area of skin. Soluble solids concentration was determined using a digital refractometer (Model PR-101; ATAGO Co., LTD., Bellevue, WA). Titratable acidity (TA) was quantified using an automated titration system (Model DL15; MettlerToledo, LLC., Columbus, $\mathrm{OH}$ ) by titrating a $10-\mathrm{mL}$ juice sample in $10 \mathrm{~mL}$ of DI water to an endpoint $\mathrm{pH}$ of 8.1 with $0.1 \mathrm{~N} \mathrm{NaOH}$. For the postharvest evaluations, half of the fruit (15/rep) were assessed when fruit had warmed to room temperature after removal from RA. The remaining 15 fruit were ripened for $5 \mathrm{~d}$ at $20{ }^{\circ} \mathrm{C}\left( \pm 1{ }^{\circ} \mathrm{C}\right)$ before evaluation.

Leaf gas exchange. Gas exchange $\left[P_{\mathrm{n}}\right.$ $\left.\left(\mu \mathrm{mol} \cdot \mathrm{m}^{-2} \cdot \mathrm{s}^{-1}\right) ; g_{\mathrm{s}}\left(\mathrm{mmol} \cdot \mathrm{m}^{-2} \cdot \mathrm{s}^{-1}\right)\right]$ was quantified using a PP systems Ciras-2 gas analyzer (PP systems, Amesbury, MA) on fully expanded leaves in basal to mid positions of current season, extension shoots in Expts. 2 and 3. For each replication and sampling date, four randomly selected leaves from exterior positions of the canopy at a height of $\approx 1.5 \mathrm{~m}$ were measured between 1200 and 1400 HR. Measurements occurred at $\approx 3$ - to 4 -d intervals. $\mathrm{CO}_{2}$ was supplied to the cuvette at 385 ppm and measurements were recorded when leaf gas exchange reached steady state in the cuvette $(\approx 60 \mathrm{~s})$. All measurements were made under near-saturated light levels (i.e., photosynthetically active radiation $>1000 \mu \mathrm{mol} \cdot \mathrm{m}^{-2} \cdot \mathrm{s}^{-1}$ ).

Solar radiation and temperature. Daily temperature and total incoming solar radiation $\left(\mathrm{W} \cdot \mathrm{m}^{-2}\right)$ data were recorded at $15-\mathrm{min}$ intervals and downloaded from the nearest weather stations to their respective orchard sites: For Expts. 1, 2, and 4, a meteorological station was located within $1 \mathrm{~km}$ of the trial sites (IFPNet); for the commercial orchard in Expt. 3, data were collected from a U.S. Bureau of Reclamation weather station (AgriMet) located $\approx 20 \mathrm{~km}$ from the site. Diurnal curves were generated between -5 and $+10 \mathrm{~d}$ from ABA application (dfa).

Statistical analyses. All statistical analyses were carried out in R-studio statistical platform. A mixed model (lm4 package) was used and blocking was assigned as a random effect. Both linear $[\operatorname{lm}()$ function] and quadratic [poly() function] models were tested and significance was reported at $P \leq 0.05$. Arccosine transformations for percent data were performed using Microsoft Excel (Microsoft Corporation, Bothell, WA) and back transformed for presentation.

\section{Results}

Flowering and fruiting. Application of ABA significantly reduced fruit set in three of the four trials (Tables 1-4). When ABA thinned, the effect was rate responsive. The severe thinning observed in Expt. 1 was explained better by a quadratic model, but generally thinning cropping responses were more strongly explained by the linear regression model. The degree of magnitude in thinning, however, was inconsistent among trials for a given dose. For example, fruit set of $200 \mathrm{ppm}$ ABA-treated trees after June drop differed markedly between trials producing drastic thinning in Expt. 3 but only slight thinning in Expt. 4 (Tables 3 and 4). The relatively light fruit set of control trees in Expt. 2 and Expt. 4 (roughly half that of Expt. 3) may have rendered chemical thinning more difficult. ABA rates $\geq 200$ ppm severely over-thinned, but in only two of the four trials (Expts. 1 and 3; Tables 1 and 3), resulting in fewer harvested fruit and lower yields despite hand thinning of control trees (Tables 1 and 3 ). At the spur level, ABA significantly increased the percentage of spurs with 0 or 1 fruit and decreased the proportion of spurs having $\geq 2$ fruit compared with the control (Fig. 1). ABA did not thin fruit in Expt. 2, irrespective of rate. Subsequently, all treatment trees were minimally hand thinned and yield differences were not detectable at harvest (Table 2). When thinning was observed, fruit weight increased with increasing ABA rate (Tables 1 and 3), except in Expt. 4 (Table 4). In Exp. 2, fruit weight, like fruit set, was unaffected by ABA treatments (Table 2). ABA-induced thinning was generally associated with an increase in return bloom; however, significantly greater return bloom tended to only occur when high ABA concentrations caused excessive thinning.

Fruit quality. Commercial harvest maturity of fruit was unaffected by ABA (determined by FF; data not shown). Fruit quality attributes at harvest and after 2 months of RA storage were not significantly affected by ABA, irrespective of rate (Table 5). ABA had no effect on fruit quality attributes after ripening, and all fruit were considered of fine eating quality (juicy and buttery texture), although a formal sensory evaluation was not performed.

Leaf gas exchange. ABA significantly lowered leaf $P_{\mathrm{n}}$ rate in Expt. 3 (Fig. 2A). Within hours from application, $P_{\mathrm{n}}$ was reduced $75 \%$ to $90 \%$ of control levels irrespective of concentration (Fig. 2A). Leaves treated with 50 and $100 \mathrm{ppm} \mathrm{ABA}$ recovered to $\approx 75 \%$ of control levels by $4 \mathrm{~d}$ from application (dfa) and fully by 8 dfa. Conversely, trees treated with higher rates of $\mathrm{ABA}$ (i.e., 200 and $400 \mathrm{ppm}$ ) required $15-20 \mathrm{dfa}$ to recover to control levels. In Expt. 2, $P_{\mathrm{n}}$ measurements were not recorded between 1 and $6 \mathrm{dfa}$ because of instrument malfunction; however, on $6 \mathrm{dfa}, P_{\mathrm{n}}$ of leaves treated with 200 ppm ABA was significantly reduced from control levels by $\approx 20 \%$ (Fig. 2B). By
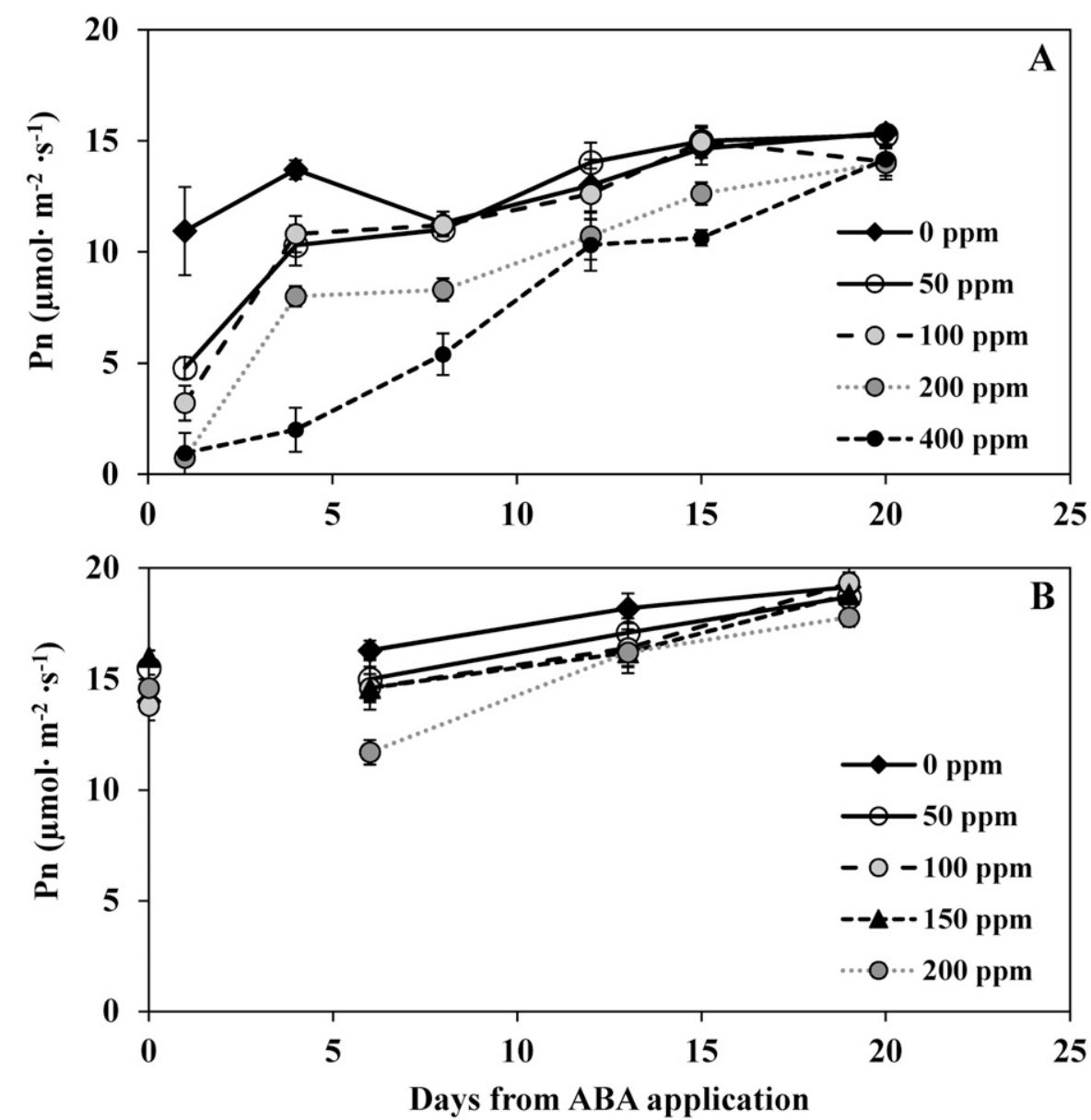

Fig. 2. The effect of abscisic acid rate on photosynthesis $\left(P_{\mathrm{n}}\right)$ of 'Bartlett' pear leaves in Expt. $3(\mathbf{A})$ and Expt. 2 (B). Measurements were taken at solar noon $( \pm 1 \mathrm{~h})$. Data are means of four replications $(n=4)$. Vertical bars are \pm 1 SE. 
day $13, P_{\mathrm{n}}$ rates of all ABA treatments were $\geq 90 \%$ of controls.

Solar radiation and temperature. Diurnal solar radiation patterns before and after ABA treatments differed drastically among trials (Fig. 3). Expt. 3 had the most days with reduced light compared with other experiments. Average daytime solar radiation was $40 \%$ to $50 \%$ of clear-sky conditions $(\approx 900$ $\mathrm{W} \cdot \mathrm{m}^{-2}$ ) five of the $10 \mathrm{~d}$ following ABA applications, with the exception of a few sunbreaks. Expts. 1 and 4 had a similar number of cloudy days within the 10-d period following treatments but differed with respect to their occurrence relative to treatment timings. In contrast, 10 consecutive cloudfree days followed ABA treatments in Expt. 2 (Fig. 3B). Daytime temperatures tended to track well with solar radiation; cloudy days had much lower average and minimum temperatures than sunny days (Fig. 4). Minimum nighttime temperatures within the 10 -d period after applications ranged from 5 to $10^{\circ} \mathrm{C}$ for Expts. 1, 3, and 4 but exceeded $10^{\circ} \mathrm{C}$ for most of the nights in Expt. 2.

\section{Discussion}

With the exception of one trial, ABA significantly thinned 'Bartlett' pears. For a given $\mathrm{ABA}$ dose, however, the rate of thinning varied among years. Greene (2012) reported consistent thinning when applying
ABA to single limbs of mature 'Bartlett' pear trees at similar concentrations to those reported herein. Generally, efficacy of a given dose of ABA was markedly higher in that study, which may be attributed to differences between the two climates. Although 'Bartlett' is not regarded as a biennial bearer, return bloom was generally improved by ABA, commensurate with the level of thinning, as previously documented (Greene, 2012). In addition to fruit abscission, Greene (2012) reported irreversible leaf yellowing and abscission at high ABA rates $(\geq 250$ ppm) despite the addition of BA, which was previously demonstrated to counteract ABAinduced yellowing of apple leaves (Greene et al., 2011). We did not include BA in our trials. We did observe severe defoliation at 400 and 500 ppm ABA (Expts. 1 and 3, an estimated one-third of the leaf population though leaf abscission data were not recorded) and slight defoliation at $250 \mathrm{ppm}$ (Expt. 1; $\approx 10 \%$ of leaves); however, appreciable leaf abscission was not observed in Expt. 4, despite treatment with 400 ppm ABA. These results indicate a potential interaction between ABA and environmental factors on leaf senescence processes. Middelberg et al. (2014) demonstrated increased ABA penetration following rewetting of ABA-treated leaves. Precipitation did accompany low solar radiation (i.e., cloudy conditions) the week after ABA applications
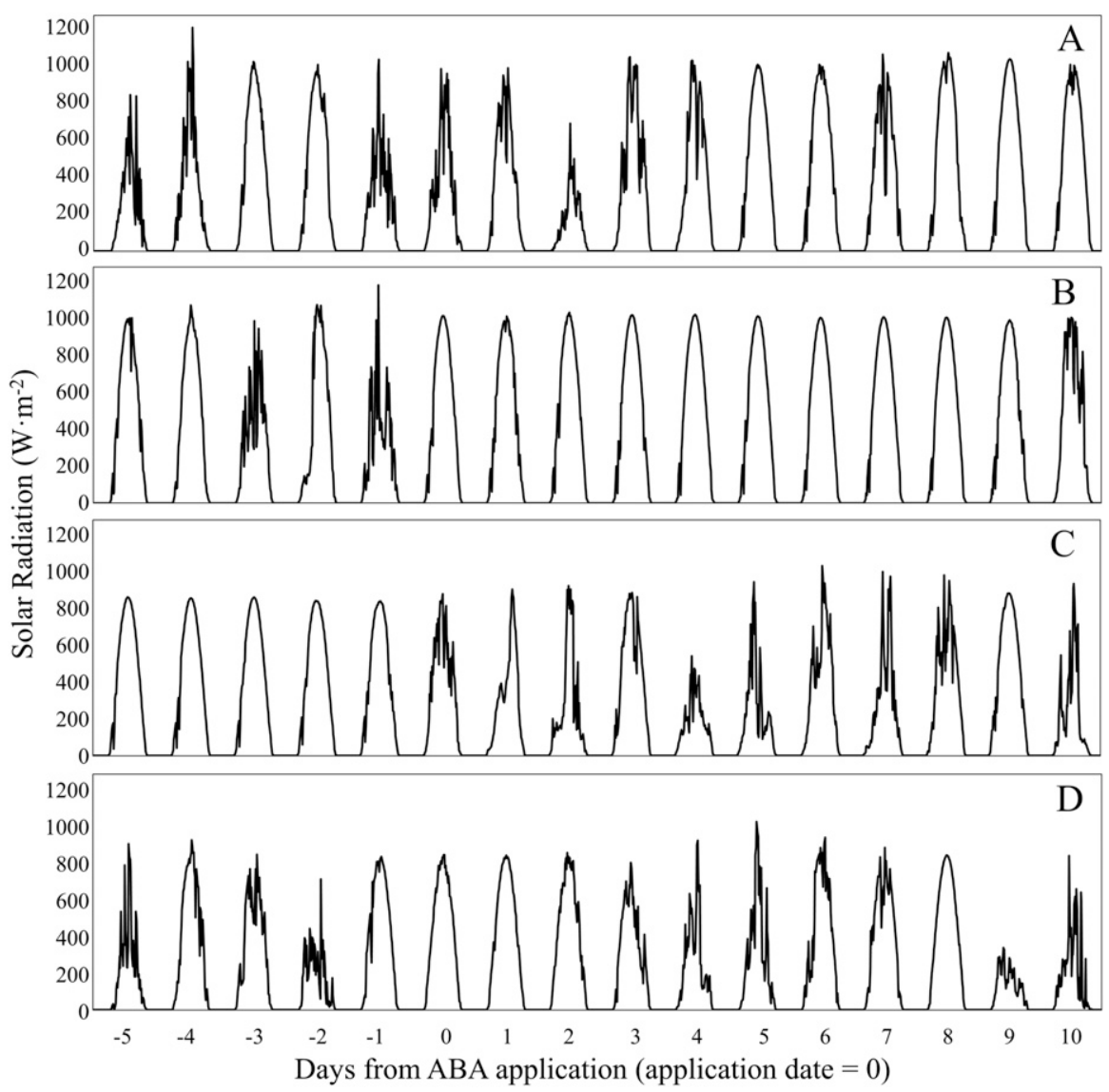

Fig. 3. Daily solar radiation $\left(\mathrm{W} \cdot \mathrm{m}^{-2}\right)$ for Expt. 1 (A), Expt. 2 (B), Expt. 3 (C), and Expt. 4 (D). Meteorological stations were located within $1 \mathrm{~km}(\mathrm{~A}, \mathrm{~B}$, and D) and $20 \mathrm{~km}$ (C) from the trial sites.

in Expts. 1 and 3 and may have enhanced ABA uptake. Leaf abscission would have certainly contributed to the excessive thinning observed in Expt. 1 and Expt. 3.

ABA-induced stomatal regulation of pear (Einhorn and Arrington, 2017) and apple (McArtney et al., 2014) was similar in magnitude and duration, with the main exception of a much stronger inhibition of pear leaf gas exchange immediately after application (Fig. 2; Einhorn and Arrington, 2017). Despite a pronounced reduction of apple leaf $g_{\mathrm{s}}$, ABA did not cause thinning of 'Morganspur Delicious' fruit (McArtney et al., 2014). We also observed disparity between $P_{\mathrm{n}}$ inhibition and thinning response of trees treated with 200 ppm ABA in Expt. 2. Although $P_{\mathrm{n}}$ data for that experiment are lacking between 1 and $6 \mathrm{dfa}$, the significantly reduced $P_{\mathrm{n}}$ on $6 \mathrm{dfa}$ is evidence that $\mathrm{ABA}$ was effectively taken up by the leaf. We can extrapolate from the proportionately similar $P_{\mathrm{n}}$ reduction of 200 ppm ABA-treated trees in Expt. 3, from their controls, that much greater photosynthetic inhibition occurred immediately after ABA application in Expt. 2. Given the putative relationship between $\mathrm{CHO}$ deficit and fruitlet thinning (Lakso, 2011; Lakso et al., 2006; Untiedt and Blanke, 2001), sufficient $\mathrm{CHO}$ was clearly available to meet fruit demand in Expt. 2, withstanding the transient supply deficit imposed by ABA.

Studies on the transport, availability, and relative dependence of reserve $\mathrm{CHO}$ and current-season photosynthate by rapidly growing apples (Corelli Grappadelli et al., 1994; Hansen, 1971; Quinlan and Preston, 1971; Stopar et al., 2001; Yuan and Greene, 2000) generally agree that current-season photosynthate disproportionately supports fruit soon after flowering. Sink strength of newly expanding leaves for assimilates was greater than developing japanese pears (Pyrus pyrifolia Nakai) within 30 dafb (Zhang et al., 2005). Apple leaves similarly compete with developing fruit. Hansen (1971) determined that $\approx 50 \%$ of the total $\mathrm{CHO}$ of the first five to six extension shoot leaves was from reserve $\mathrm{CHO}$ pools. Moreover, export of $\mathrm{CHO}$ from extension shoots did not occur until 10-12 leaves had emerged (Johnson and Lakso, 1986). Developing fruitlets, therefore, rely heavily on spur leaf $P_{\mathrm{n}}$ (Wünsche et al., 1996). Leaf emergence of european pear does not occur until postbloom, which is considerably later than that of apple. In the present study, ABA was applied between 10 and 20 dafb, when extension shoots are typically $10-20 \mathrm{~cm}$ long and possess $\approx 3-6$ leaves (Einhorn, unpublished data), potentially providing longer lasting reserves to support early fruitlet development. Furthermore, the vast difference in tree size among our trials and, potentially CHO reserves, was noteworthy: $\approx 10$-yearold trees (i.e., Expts. 1 and 3) seemed easier to thin than $\approx 20$-year-old trees, which were either insensitive to ABA (Expt. 2) or required markedly higher $\mathrm{ABA}$ rates to induce moderate thinning (Expt. 4). However, the strong $\mathrm{ABA}$ thinning response of mature 

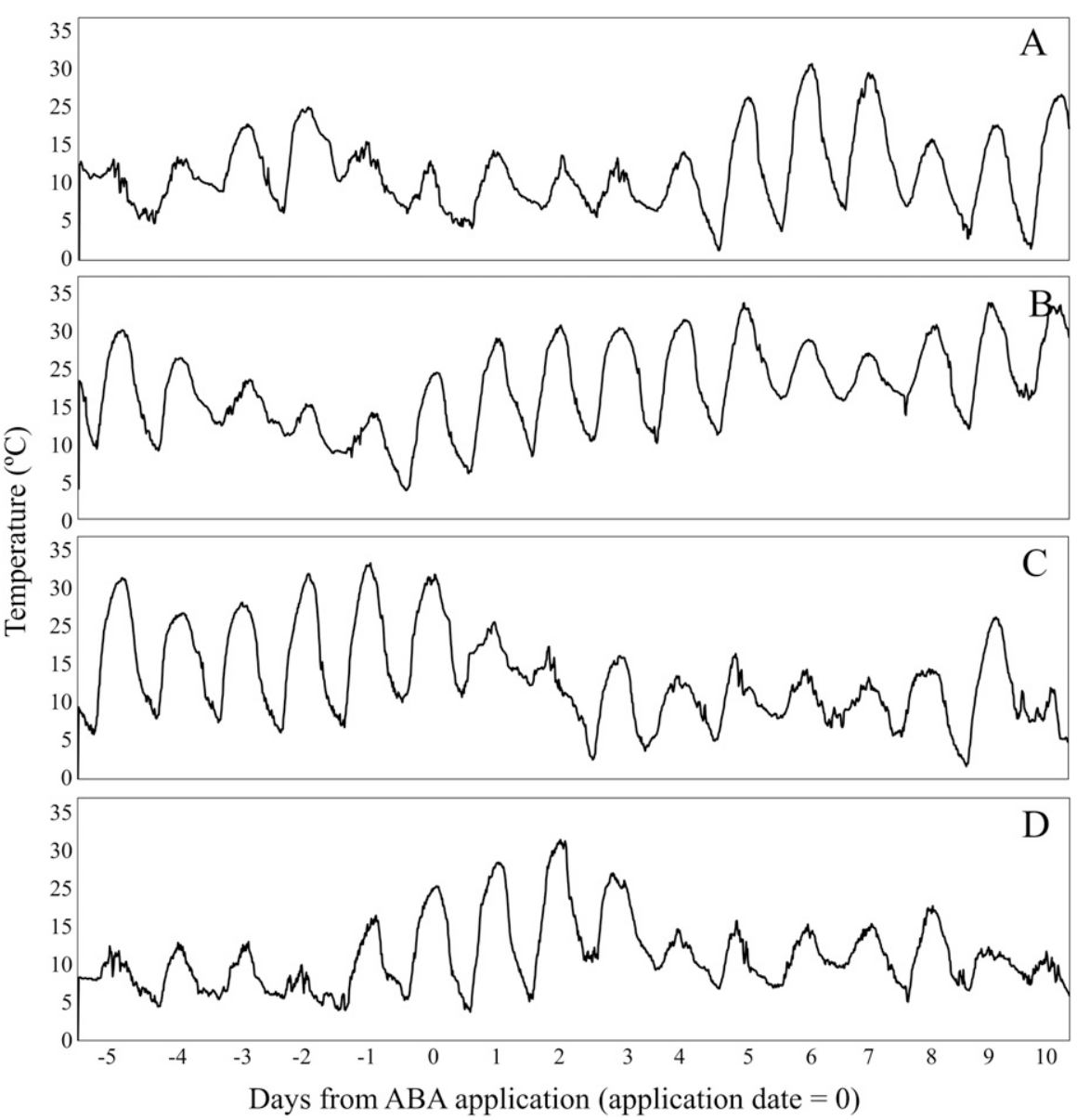

Fig. 4. Daily temperature for Expt. 1 (A), Expt. 2 (B), Expt. 3 (C), and Expt. 4 (D). Meteorological stations were located within $1 \mathrm{~km}(\mathbf{A}, \mathbf{B}$, and $\mathbf{D})$ and $20 \mathrm{~km}(\mathbf{C})$ from the trial sites.
'Bartlett' pear trees on seedling rootstock (Greene, 2012) with, presumably, high CHO reserves does not support this contention. In addition, less-severe thinning in Expt. 4 may have been due to the earlier application timing ( $8 \mathrm{dafb}$ as opposed to $\approx 20 \mathrm{dafb}$ in all other trials). Indeed, Greene (2012) demonstrated greater ABA efficacy at $10 \mathrm{~mm}$ 'Bartlett' fruit diameter compared with petal fall applications. A change in environmental factors from year to year after thinning applications may have additionally modulated the response to $\mathrm{ABA}$ as observed with other chemical compounds (Greene, 2002; Stover and Greene, 2005).

Ten consecutive days of high solar radiation following ABA sprays in Expt. 2 suggests that a surplus in CHO supply may have increased the difficulty to chemically thin pears. In contrast, reduced light in the week after ABA applications in Expts. 1, 3, and 4 may have resulted in $\mathrm{CHO}$ deficits, increasing the thinning activity of ABA. Cloudy conditions favor enhanced chemical thinning (Stover and Greene, 2005) owed, in part, to reduced $\mathrm{CHO}$ supply and altered CHO partitioning (Corelli Grappadelli et al., 1994). A strong correlation between $P_{\mathrm{n}}$ inhibition and fruit abscission was observed for 'Bartlett' pear trees treated with either ABA or shade (Einhorn and Arrington, 2017). Fifteen days of moderate shade ( $44 \%$
M. $\times$ domestica Borkh. have similar centers of origin (Westwood, 1993), nearly equivalent photosynthetic light response behavior (Einhorn et al., 2012; Lakso, 1994), and early-season fruit growth and development patterns (Westwood, 1993). Based on data from apple and the previous assumptions, maximum daytime temperatures during Expt. 2 of 25 to $32{ }^{\circ} \mathrm{C}$ and nighttime temperatures between 5 and 9 dfa (i.e., $>15^{\circ} \mathrm{C}$ ) would have reduced available $\mathrm{CHO}$ because of increased respiratory costs. Conversely, low day and night temperatures following ABA sprays in Expts. 1 and 3 would not have been expected to increase fruit growth or respiratory demand. These conditions contrast those in the Eastern United States where cloudy days are often accompanied by high temperatures during early fruit development (D. Greene, personal communication). Notwithstanding extreme temperature fluctuations, pear fruit set may be more sensitive to light than temperature. Indeed, fruit set and light interception of mature Anjou pear trees were markedly improved when reflective fabrics were applied at full bloom (Einhorn et al., 2012).

ABA likely thinned 'Bartlett' pear by inducing a short-term carbon stress. However, the effect on carbon balance seems to be relatively short lived and it is unclear whether ABA thins solely by reducing $P_{\mathrm{n}}$. Biotic and abiotic factors (light and carbon reserves) may additionally alter the thinning response. In high-light environments, ABA might not provide sufficient $P_{\mathrm{n}}$ inhibition to effectively thin fruit. Because $\geq 250 \mathrm{ppm}$ ABA induced significant phytotoxicity and excessive leaf abscission, increasing ABA rates when conditions are less conducive to thinning (i.e., high light) is not an effective option. In these regions, alternative thinning compounds should be used, or, potentially, successive applications of 200 ppm ABA.

\section{Literature Cited} 2017). Additive thinning effects of shade and chemical thinners were observed when the thinner's mode of action was not $P_{\mathrm{n}}$ inhibition, such as carbaryl (Byers et al., 1990, 1991; Lehman et al., 1987) and ethephon (Lehman et al., 1987). Elucidation of the complex interactions among environmental and genetic factors and their effect on chemical thinner efficacy will require controlled environment studies.

Temperature affects $\mathrm{CHO}$ metabolism and growth potential of fruits. Optimum net canopy assimilation and dry matter production of apple trees occur around 20 to $25^{\circ} \mathrm{C}$ and 10 to $15{ }^{\circ} \mathrm{C}$ for day and night, respectively (Lakso, 2011). Higher temperatures, especially at night, were associated with increased thinning of apples (Byers, 2002) likely because of higher respiration. $P_{\mathrm{n}}$ response to temperature was similar for leaves of apple and asian pear (Pyrus serotina L.) (Higgins et al., 1992). Comparable data are not available for european pear. It is not unreasonable, however, to expect similar $P_{\mathrm{n}}$ :temperature thresholds between apple and pear because Pyrus communis L. and the major species hybridized to develop

Asín, L., P. Vilardell, J. Bonany, and S. Alegre. 2009. Effect of 6-BA, NAA and their mixtures on fruit thinning and fruit yield in 'Conference' and 'Blanquilla' pear cultivars. Acta Hort. 884:379-382.

Bangerth, F. 2000. Abscission and thinning of young fruit and their regulation by plant hormones and bioregulators. Plant Growth Regulat. 31:43-59.

Black, B., P.D. Petracek, and M.J. Bukovac. 1995. The effect of temperature or uptake of NAA by 'Redchief Delicious' apple leaves. J. Amer. Soc. Hort. Sci. 120:441-445.

Bound, S.A. and L. Mitchell. 2002. The effect of blossom desiccants on crop load of 'Packham's Triumph’ pear. Acta Hort. 596:729-733.

Bubán, T. 2000. The use of benzyladenine in orchard fruit growing: A mini review. Plant Growth Regulat. 32:381-390.

Byers, R.E. 2002. Influence of temperature and darkness on apple fruit abscission and chemical thinning. J. Tree Fruit Prod. 3:41-53.

Byers, R.E., J.A. Barden, and D.H. Carbaugh. 1990. Thinning of spur 'Delicious' apples by shade, terbacil, carbaryl, and ethephon. J. Amer. Soc. Hort. Sci. 115:9-13.

Byers, R.E., D.H. Carbaugh, C.N. Presley, and T.K. Wolf. 1991. The influence of low light on apple fruit abscission. J. Hort. Sci. 66(1):7-17. 
Corelli Grappadelli, L., A.N. Lakso, and J.A. Flore. 1994. Early season patterns of photosynthate partitioning in exposed and shaded apple branches. J. Amer. Soc. Hort. Sci. 119:596-603.

Correia, M.J., M.L. Rodrigues, M.L. Osório, and M.M. Chaves. 1999. Effects of growth temperature on the response of lupin stomata to drought and abscisic acid. Austral. J. Plant Physiol. 26:549-559.

Curetti, M., R. Rodríguez, C. Magdalena, and A. Rodríguez. 2010. Effect of concentration, application volume and addition of a surfactant on response to benzyladenine as thinning agent in 'Williams' pears. Acta Hort. 909:395-401.

Davies, W.J. and J. Zhang. 1989. Chemical regulation of growth and physiology in drying soil: The case for abscisic acid. Curr. Top. Plant Biochem. Physiol. 8:100-109.

Dussi, M.C. 2011. Sustainable use of plant bioregulators in pear production. Acta Hort. 909:353-367.

Edgerton, L.J. 1971. Apple abscission. HortScience 6:378-382.

Edgerton, L.J. and C.W. Haeseler. 1959. Some factors influencing the absorption of naphthaleneacetic acid and naphthaleneacetamide by apple leaves. Proc. Amer. Soc. Hort. Sci. 74:54-60.

Einhorn, T.C. and M. Arrington. 2017. ABA and shade inhibit photosynthesis and increase abscission of 'Bartlett' pears but are not additive. J. Plant Growth Reg., doi: 10.1007/s00344017-9729.

Einhorn, T.C., J. Turner, and D. Laraway. 2012. Effect of reflective fabric on yield of mature 'd'Anjou' pear trees. HortScience 47:15801585.

Ellis, K., T.A. Baugher, and K. Lewis. 2010. Results from survey instruments used to assess technology adoption for tree fruit production. HortTechnology 20:1043-1048.

Gimenez, G., P. Reeb, M.C. Dussi, F. Elosegui, P. Siviero, S. Fantaguzzi, and D. Sugar. 2009. Optimizing benzyladenine application timing in 'Williams' pear. Acta Hort. 884:265-272.

Giovanaz, M.A., D. Spagnol, J. Bartz, M. Pasa, F.C. Chaves, and J.C. Fachinello. 2015. Abscisic acid as a potential chemical thinner for peach. Pesqui. Agropecu. Bras. 50(10):989992.

Greene, D.W. 2002. Chemicals, timing, and environmental factors involved in thinner efficacy on apple. HortScience 37:477-481.

Greene, D.W. 2012. Influence of abscisic acid and benzyladenine on fruit set and fruit quality of 'Bartlett' pears. HortScience 47:1607-1611.

Greene, D.W. and M.J. Bukovac. 1971. Factors influencing the penetration of naphthaleneacetamide into leaves of pear (Pyrus communis L.). J. Amer. Soc. Hort. Sci. 96:240-246.

Greene, D.W., J.R. Schupp, and H.E. Winzeler. 2011. Effect of abscisic acid and benzyladenine on fruit set and fruit quality of apples. HortScience 46:604-609.

Hansen, P. 1971. ${ }^{14} \mathrm{C}$-studies on apple trees. VII. The early seasonal growth in leaves, flowers and shoots as dependent upon current photo- synthates and existing reserves. Physiol. Plant. 25:469-473.

Higgins, S.S., F.E. Larsen, R.B. Bendel, G.K. Radamaker, J.H. Bassman, W.R. Bidlake, and A.A. Wir. 1992. Comparative gas exchange characteristics of potted, glasshouse-grown almond, apple, fig, grape, olive, peach and Asian pear. Scientia Hort. 52:313-329.

Johnson, R.S. and A.N. Lakso. 1986. Carbon balance model of a growing apple shoot: Development of the model. J. Amer. Soc. Hort. Sci. 111:160-164.

Lakso, A.N. 1994. Apple. In: B. Schaffer and P.C. Anderson (eds.). Handbook of environmental physiology of fruit crops Vol. 1: Temperate crops. CRC Press, Boca Raton, FL.

Lakso, A.N. 2011. Early fruit growth and drop-the role of carbon balance in the apple tree. Acta Hort. 903:733-742.

Lakso, A.N., T.L. Robinson, and D.W. Greene. 2006. Integration of environment, physiology and fruit abscission via carbon balance modelingImplications for understanding growth regulator responses. Acta Hort. 727:321-326.

Lehman, L.J., C.R. Unrath, and E. Young. 1987. Chemical fruit thinning response of spur delicious apple as influenced by light intensity and soil moisture. HortScience 22:214-215.

Lombard, P.B. and J.H. Grim. 1966. Would you believe: Chemical thinning of Bartlett's? Proc. Oreg. Hort. Soc. 58:27-30.

Luckwill, L.C. and C.P. Lloyd-Jones. 1962. The absorption, translocation and metabolism of 1-naphthaleneacetic acid applied to apple leaves. J. Hort. Sci. 37:190-206.

Maas, F.M. and P.A.H. van der Steeg. 2011. Chemical thinning of 'Conference' pear. Acta Hort. 884:293-304.

McArtney, S.J., S.R. Abrams, D.D. Woolard, and P.D. Petracek. 2014. Effects of S-abscisic acid and $(+)-8^{\prime}$-Acetylene abscisic acid on fruit set and stomatal conductance in apple. HortScience 49:763-768.

Middelberg, M., M. Knoche, and P.D. Petracek. 2014. Effects of $\mathrm{pH}$, humidity, and rewetting on cuticular penetration of ABA. Acta Hort. 1042:143-150.

Ngugi, H.K. and J.R. Schupp. 2009. Evaluation of the risk of spreading fire blight in apple orchards with a mechanical string blossom thinner. HortScience 44:862-865.

Quinlan, J.D. and A.P. Preston. 1971. The influence of shoot competition of fruit retention and cropping of apple trees. J. Hort. Sci. 46(4):525534.

Reighard, G.L. and W.G. Henderson. 2012. Mechanical blossom thinning in South Carolina peach orchards. Acta Hort. 965:117-121.

Schupp, J.R., T.A. Baugher, S.S. Miller, R.M. Harsh, and K.M. Lesser. 2008. Mechanical thinning of peach and apple trees reduces labor input and increases fruit size. HortTechnology 18:660-670.

Schupp, J.R. and T.M. Kon. 2014. Mechanical blossom thinning of 'GoldRush'/M. 9 apple trees with two string types and two timings. J. Amer. Pomol. Soc. 68(1):24-31.

Seehuber, C., L. Damerow, A. Kunz, and M.M. Blanke. 2015. Mechanical thinning of 'Lucas' and 'Conference' pear improves fruit quality. Acta Hort. 1094:289-295.

Stopar, M., M. Resnik, and V.Ž. Pongrac. 2001. Non-structural carbohydrate status and $\mathrm{CO} 2$ exchange rate of apple fruitlets at the time of abscission influenced by shade, NAA or BA. Scientia Hort. 87(1):65-76.

Stover, E.W. and D.W. Greene. 2005. Environmental effects on the performance of foliar applied plant growth regulators: A review focusing on tree fruits. HortTechnology 15:214-221.

Taiz, L. and E. Zeiger. 2010. Plant physiology. 5th ed. Sinauer Associates Inc., Sunderland, MA.

Theron, K.I., T.G. Chabikwa, and G.G.A. Lötze. 2011. Evaluation of 6-benzyladenine (BA) and naphthylacetamide (NAD) as post-bloom thinning compounds for 'Early Bon Chrétien' pear. Acta Hort. 909:387-393.

Untiedt, R. and M. Blanke. 2001. Effects of fruit thinning agents on apple tree canopy photosynthesis and dark respiration. Plant Growth Regulat. 35:1-9.

U.S. Department of Agriculture National Agricultural Statistics Service. 2016. Agricultural Statistics 2016. 10 Aug. 2017 https://www.nass. usda.gov/Publications/Ag_Statistics/2016/ Chapter05.pdf.

Wells, D.J., C. Wells, and C.F. Seavert. 1998. The economics of hand-thinning ' $d$ 'Anjou' pears in the Hood River valley of Oregon, USA. Acta Hort. 475:405-411.

Wertheim, S.J. 2000. Developments in the chemical thinning of apple and pear. J. Plant Growth Regulat. 34:321-331.

Westwood, M.N. 1993. Temperate-zone pomology: Physiology and culture. 3rd ed. Timber Press, Portland, OR.

Wünsche, J.N., A.N. Lakso, T.L. Robinson, F. Lenz, and S.S. Denning. 1996. The bases of productivity in apple production systems: The role of light interception by different shoot types. J. Amer. Soc. Hort. Sci. 121:886-893.

Yoder, K., R. Yuan, L. Combs, R. Byers, J. McFerson, and T. Schmidt. 2009. Effects of temperature and the combination of liquid lime sulfur and fish oil on pollen germination, pollen tube growth, and fruit set in apples. HortScience 44:1277-1283.

Yuan, R. and D.W. Greene. 2000. Benzyladenine as a chemical thinner for 'McIntosh' apples. I. Fruit thinning effects and associated relationships with photosynthesis, assimilate translocation, and nonstructural carbohydrates. J. Amer. Soc. Hort. Sci. 125:169-176.

Zhang, C., K. Tanabe, F. Tamura, A. Itai, and S. Wang. 2005. Spur characteristics, fruit growth, and carbon partitioning in two late-maturing Japanese pear (Pyrus pyrifolia Nakai) cultivars with contrasting fruit size. J. Amer. Soc. Hort. Sci. 130:252-260. 